\title{
A new type of banana shape bifunctional monomer of ester chalcones
}

\author{
Zainab Ngaini*, Chua Mei Chee and Lim Lian Chin \\ Department of Chemistry, Faculty of Resource Science and Technology, Universiti Malaysia Sarawak, 94300 Kota Samarahan, Sarawak, Malaysia \\ *Corresponding Author: nzainab@frst.unimas.my (Z. Ngaini)
}

\section{Article history :}

Received 21 March 2013

Revised 1 July 2013

Accepted 19 July 2013

Available online 1 September 2013

\section{GRAPHICAL ABSTRACT}

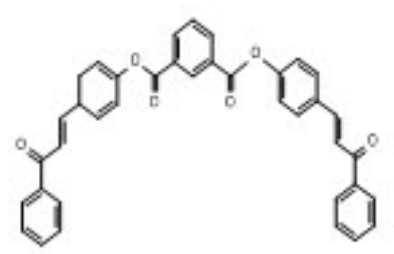

\section{ABSTRACT}

A synthesis of a new type of chalcone analogue banana-shaped liquid crystals compounds is described. The approach involved the reaction of hydroxyl chalcones with isophthaloyl dichloride to form benzene1,3-dicarbonyl-bis-1-(4-alkoxyphenyl)-3-(4-hydroxylphenyl)prop-2-en-1-one (7a-c and 8a-c) having two chalcone units via esterification reaction. The hydroxyl chalcones, which differ in the length of alkyl group, $\mathrm{C}_{\mathrm{n}} \mathrm{H}_{2 \mathrm{n}+1}$, where $\mathrm{n}=10,12$ and 14 were synthesised via Claisen Schmidt condensation prior to the reaction with isophthaloyl dichloride. The reaction was a catalyst dependence. No sign of product was formed by employing $\mathrm{NaH}(60 \%)$. It was only occurred in the presence of $\mathrm{NaH}(95 \%)$ to afford banana shape bi-functional monomer of ester chalcone 7a-c and 8a-c. The synthesized compound was characterized by ${ }^{1} \mathrm{H}$ and ${ }^{13} \mathrm{C}$ Nuclear Magnetic Resonance (NMR), and Fourier Transform Infrared (FTIR).

Keywords: Chalcones, banana shape liquid crystals, alkyl chains, ester

(C) 2014 Penerbit UTM Press. All rights reserved http://dx.doi.org/10.11113/mjfas.v10n2.55

\section{INTRODUCTION}

Liquid crystal technology has been widely applied in device technology. Both fluidity and crystalline properties of liquid crystal facilitate better control over alignment when applied to device. The advantages of liquid crystals for these applications such as faster switching times, a wider viewing angle, continuous gray level, improved transmittance of the clear state, approximately no threshold voltage and low power consumption [1].

Series of linear shape of mesogens based on chalcone has been studied for their liquid crystal behavior [2,3]. Chalcone derivatives were reported for excellent nonlinear optic property [4] and liquid crystal displays [5,6]. Chalcones has been used in promoting light transmittance [7] and crystallability [8].

In recent years, banana-shaped liquid crystals have been given much attention in various aspects such as fast polarization reorientation, ferroelectricity and antiferroelectricity, and small threshold voltage when applied to liquid crystal display mode [9]. Banana-shaped liquid crystals have also been identified as interesting compounds due to their unexpected electro-optical properties, polarity and chirality [10].

In this paper, we describe the preparation of a new type banana shape compound of benzene-1,3-dicarbonylbis-1-(4-alkoxyphenyl)-3-(4-hydroxylphenyl)prop-2-en-1one 5 a-c possessing alkyl chains of varying length from $\mathrm{C}_{10}$ to $\mathrm{C}_{14}$ which potentially used for liquid crystal studies.

\section{EXPERIMENTAL}

\subsection{Materials and characterizations}

4-hydroxybenzaldehyde, 4-hydroxyacetophenone, 1-bromoalkane, 4-hydroxychalcone and isophthaloyl dichloride were obtained from Merck Company and used as received. THF was dried over sodium and benzophenone. All other reagents and solvent were used as received. Infrared spectra were recorded on a Perkin Elmer 1605 Fourier Transform Infra-Red Spectrophotometer. ${ }^{1} \mathrm{H}$ and ${ }^{13} \mathrm{C}$ NMR spectra were be recorded using JEOL ECA 500 Spectrometer operating at $500 \mathrm{MHz}$ for ${ }^{1} \mathrm{H}$ and $125 \mathrm{MHz}$ for ${ }^{13} \mathrm{C}$ with chemical shifts reported relative to $\mathrm{CDCl}_{3}$ as standard reference.

\subsection{Synthesis of 4-hydroxychalcones}

Potassium hydroxide $(\mathrm{KOH})(1.68 \mathrm{~g}, 30 \mathrm{mmol})$ in ethanol $(90 \mathrm{~mL}, 95 \%)$ was stirred for $30 \mathrm{~min}$. 4hydroxyacetophenone $(4.08 \mathrm{~g}, 30 \mathrm{mmol})$ and benzaldehyde (3.66 g, $30 \mathrm{mmol})$ were added to the solution mixture respectively. The reaction mixture was stirred at room temperature for $18 \mathrm{~h}$. The mixture was cooled in an ice bath and acidified with hydrochloric acid $(\mathrm{HCl})(12 \mathrm{M})$. The precipitate was filtered, washed and dried. Recrystallization was performed from hexane: ethanol $(7: 1)$ to afford compound 1 as light yellow solid, 2.02 g, 30 \%, m.p. 175.0- 
177.0 ${ }^{\circ} \mathrm{C} . \quad \mathrm{V}_{\max }\left(\mathrm{KBr} / \mathrm{cm}^{-1}\right) 3140(-\mathrm{OH}), 1646(\mathrm{C}=\mathrm{O})$, 980(trans $\mathrm{CH}=\mathrm{CH})$ and 823 (para disub benzene). $\delta_{\mathrm{H}}(500$ $\left.\mathrm{MHz}, \mathrm{CDCl}_{3}\right) 8.10\left(\mathrm{~d}, J\right.$ 8.6, 2H, $\left.\mathrm{H}_{1}-3\right), 7.85(\mathrm{~d}, J 15,1 \mathrm{H}$, $\left.\mathrm{H}_{1}-\mathrm{a}\right), 7.81-7.83$ (m, 3H, $\mathrm{H}_{1}-3$ '\& 4'), 7.75 (d, J 15, 1H, $\mathrm{H}_{1-}$ b), $7.43\left(\mathrm{~d}, J 6.9,2 \mathrm{H}, \mathrm{H}_{1}-2\right), 6.96\left(\mathrm{~d}, J 8.05,2 \mathrm{H}, \mathrm{H}_{1}-2\right.$ ').

\subsection{Synthesis of benzene-1,3-dicarbonyl-bis-4- chalcone (2)}

\section{Attempted Strategy 1}

4-hydroxychalcone $(0.11 \mathrm{~g}, \quad 0.50 \mathrm{mmol})$ and tetrahydrofuran (THF) (30 mL) was added to sodium hydride $(\mathrm{NaH})(0.01 \mathrm{~g}, 0.50 \mathrm{mmol}, 60 \%)$ and stirred for 1 $\mathrm{h}$ at room temperature. Benzene-1,3-dicarbonyl dichloride $(0.05 \mathrm{~g}, 0.25 \mathrm{mmol})$ in THF $(20 \mathrm{~mL})$ was added to the mixture and stirred for $6 \mathrm{~h}$ at room temperature. The TLC showed no sign of product formed after prolonged stirring for $24 \mathrm{~h}$. The reaction was continued no further.

\section{Strategy 2}

4-hydroxychalcone $(0.11 \mathrm{~g}, 0.50 \mathrm{mmol})$ and THF (30 $\mathrm{mL})$ was added to sodium hydride $(\mathrm{NaH})(0.01 \mathrm{~g}, 0.50$ mmol, $95 \%$ ) and stirred for $1 \mathrm{~h}$ at room temperature. Benzene-1,3-dicarbonyl dichloride ( $0.05 \mathrm{~g}, 0.25 \mathrm{mmol})$ in THF $(20 \mathrm{~mL})$ was added to the mixture. The mixture was refluxed for $8 \mathrm{~h}$. The mixture was cooled to room temperature, filtered, and washed with distilled water and methanol. Dichloromethane (DCM) and distilled water were used to extract the organic layer. The organic layer was dried, filtered and concentrated in vacuo. The crude was purified from hexane: DCM (3:1) to give 2 as pale yellowish oil $(0.10 \mathrm{~g}, 34.9 \%) . \mathrm{v}_{\max }\left(\mathrm{KBr} / \mathrm{cm}^{-1}\right) 1727(\mathrm{C}=\mathrm{O}$ ester $)$, $1646(\mathrm{C}=\mathrm{O}$ carbonyl), 1222(C-O-C), $980(\mathrm{C}=\mathrm{C}), 823$ (para disub benzene). $\delta_{\mathrm{H}}\left(500 \mathrm{MHz}, \mathrm{DMSO}_{6}\right) 6.88$ (d, $J$ 8.6, $4 \mathrm{H}, \mathrm{Ar}-\mathrm{H}_{2}$ ), 7.44 (d, 4H, Ar-H $\left.3^{\prime}\right), 7.57$ (t, J 7.45, 1H, Ar- $\mathrm{H}_{4}$ ), $6.96(\mathrm{~d}, 2 \mathrm{H}, J 15 \mathrm{~Hz}, 2 \mathrm{x}$ trans-olefinic $\mathrm{H}), 7.73$ (d, J 6.85, $1 \mathrm{H}, \mathrm{Ar}-\mathrm{H}_{2}$ ) $)$ 7.85-7.87(m, 6H, Ar- $\mathrm{H}_{3 " \& 4}$ "), 7.89(d, 2H, $J 15$ $\mathrm{Hz}, 2 \mathrm{x}$ trans-olefinic H), 8.08(d, J 8.6, 2H, $\left.\mathrm{Ar}-\mathrm{H}_{3}\right), 8.49$ (s, $\left.1 \mathrm{H}, \mathrm{Ar}-\mathrm{H}_{1}\right)$.

\subsection{Synthesis of alkyloxyphenyl-ethanone (3a-3c)}

\section{General procedure}

Bromoalkane (72 mmol), 4-hydroxyacetophenone (72 mmol), $\mathrm{K}_{2} \mathrm{CO}_{3}(72 \mathrm{mmol})$, and TBAI $(6 \mathrm{mmol})$ in MEK $(200 \mathrm{~mL})$ were heated at reflux for $5 \mathrm{~h}$. The mixture was filtered and cooled to room temperature. Water $(30 \mathrm{~mL})$ was added to the filtrate, and the layers separated. The aqueous layer was extracted with dichloromethane $(2 \times 30 \mathrm{~mL})$. The combined layers were washed with water $(2 \times 20 \mathrm{~mL})$, dried $\left(\mathrm{MgSO}_{4}\right)$, filtered, and concentrated in vacuo. The crude was recrystallized from ethanol to give $\mathbf{3 a - 3 c}$.

1-(4-Decyloxyphenyl)-ethanone (3a)
Bromodecane (12.40 mL, $60 \mathrm{mmol})$. Yield: $9.08 \mathrm{~g}, 66 \%$. FTIR and NMR data were consistent with the reported literature [11].

1-(4-Dodecyloxyphenyl)-ethanone (3b)

Bromododecane (14.38 mL, $60 \mathrm{mmol}$ ). Yield: $13.55 \mathrm{~g}$, 89\%. FTIR and NMR data were consistent with the reported literature [11].

\section{1-(4-Tetradecyloxyphenyl)-ethanone (3c)}

Bromotetradecane (14.38 mL, $60 \mathrm{mmol})$. Yield: $13.80 \mathrm{~g}$, $83 \%$. FTIR and NMR data were consistent with the reported literature [11].

\subsection{Synthesis of (E)-1-[4-(alkyloxy)phenyl]-3-[4- hydroxyphenyl]prop-2-en-1-one (4a-4c)}

\section{General procedure}

A mixture of 4-hydroxybenzaldehyde $(12.5 \mathrm{mmol})$ and 3a-c $(12.5 \mathrm{mmol})$ in $35 \mathrm{~mL}$ of methanol was added under stirring to a solution of $\mathrm{KOH}(2.52 \mathrm{~g})$ in methanol (10 $\mathrm{mL}$ ). The mixture was heated at reflux for $10 \mathrm{~h}$. The reaction was cooled to room temperature and acidified with cold diluted $\mathrm{HCl}(2 \mathrm{~N})$. The resulting precipitate was filtered, washed, and dried. The crude was recrystallized from hexane:ethanol (7:1) to give $\mathbf{4 a - 4 c}$.

\section{((E)-1-(4-decyloxyphenyl)-3-(4-hydroxyphenyl)prop-2-} en-1-one (4a)

Compound 4a was obtained as yellow crystals $(5.74 \mathrm{~mL}, 20$ mmol). Yield (2.66 g, 35\%). FTIR and NMR data were consistent with the reported literature [11].

\section{(E)-1-[4-(Dodecyloxy)phenyl]-3-[4-hydroxyphenyl]prop- 2-en-1-one (4b)}

Compound $\mathbf{4 b}$ was obtained as yellow crystals. Yield: $44 \%$. FTIR and NMR data were consistent with the reported literature [11].

\section{(E)-1-[4-(Tetradecyloxy)phenyl]-3-[4-hydroxyphenyl] prop-2-en-1-one (4c)}

Compound 4c was obtained as yellow crystals. Yield: $39 \%$. FTIR and NMR data were consistent with the reported literature [11].

\subsection{Synthesis of alkyloxybenzaldehyde (5a-5c)}

\section{General procedure}

Bromoalkane (60 mmol), 4-hydroxybenzaldehyde (60 mmol), $\mathrm{K}_{2} \mathrm{CO}_{3}(60 \mathrm{mmol})$, and TBAI $(6 \mathrm{mmol})$ in MEK $(200 \mathrm{~mL})$ were heated at reflux for $5 \mathrm{~h}$. The mixture was filtered and cooled to room temperature. Water $(30 \mathrm{~mL})$ was added to the filtrate, and the layers separated. The aqueous layer was extracted with dichloromethane $(2 \times 30 \mathrm{~mL})$. The combined layers were washed with water $(2 \times 20 \mathrm{~mL})$, dried $\left(\mathrm{MgSO}_{4}\right)$, filtered, and concentrated in vacuo. The crude product was purified by column chromatography (eluting 
with 1:20 ethyl acetate:petroleum ether). The same general procedure gave compounds $\mathbf{5 a - c .}$

\section{4-Decyloxybenzaldehyde (5a)}

Bromododecane (12.40 mL, $60 \mathrm{mmol})$. Yield: $8.69 \mathrm{~g}, 66 \%$. FTIR and NMR data were consistent with the reported literature [12].

\section{4-Dodecyloxybenzaldehyde (5b)}

Bromododecane (14.38 mL, $60 \mathrm{mmol}$ ). Yield: $13.03 \mathrm{~g}, 90 \%$. The FTIR and NMR data were consistent with the reported literature [12].

\section{4-Tetradecyloxybenzaldehyde (5c)}

Bromotetradecane (16.31 mL, $60 \mathrm{mmol})$.Yield: $11.78 \mathrm{~g}$, $74 \%$. The FTIR and NMRdata were consistent with the reported literature [12].

\subsection{Synthesis of (E)-3-(4-alkyloxyphenyl)-1-(4- hydroxyphenyl)prop-2-en-1-one (6a-6c)}

\section{General procedure}

A mixture of 4-hydroxyacetophenone (30 mmol) and 6a-c $(30 \mathrm{mmol})$ in $90 \mathrm{~mL}$ of methanol was added under stirring to a solution of $\mathrm{KOH}(6.06 \mathrm{~g}, 108 \mathrm{mmol})$ in methanol $(10 \mathrm{~mL})$. The mixture was heated at reflux for 10 $\mathrm{h}$. The reaction was cooled to room temperature and acidified with cold diluted $\mathrm{HCl}(2 \mathrm{~N})$. The resulting precipitate was filtered, washed, and dried. The crude was recrystallized from hexane:ethanol $(7: 1)$ to give $\mathbf{6 a - 6 c}$.

\section{(E)-3-(4-Decyloxyphenyl)-1-(4-hydroxyphenyl)prop-2-en- 1-one (6a)}

6a $(5.25 \mathrm{~mL}, 20 \mathrm{mmol})$ Yield: $6.83 \mathrm{~g}, 54 \%$. The FTIR and NMR data were consistent with the reported literature [12].

\section{(E)-3-(4-Dodecyloxyphenyl)-1-(4-hydroxyphenyl)prop-2- en-1-one (6b)}

6b (5.81 mL, $20 \mathrm{mmol})$. Yield: $8.32 \mathrm{~g}, 52 \%$. The FTIR and NMR data were consistent with the reported literature [12].

\section{(E)-3-(4-Tetradecyloxyphenyl)-1-(4-hydroxyphenyl)- prop-2-en-1-one (6c)}

6b (5.81 mL, $20 \mathrm{mmol})$. Yield: $8.32 \mathrm{~g}, 52 \%$. The FTIR and NMR data were consistent with the reported literature [12]

\subsection{Synthesis of bifunctional monomer of ester} chalcones (7a-7c) and (8a-8c)

\section{Benzene-1,3-dicarbonyl-bis-1-(4-decyloxyphenyl)-3-(4-} hydroxyphenyl)prop-2-en-1-one (7a)

$\mathrm{NaH}(0.03 \mathrm{~g}, 1.2 \mathrm{mmol}, 95 \%)$ was added into a solution of 4a $(0.38 \mathrm{~g}, 1.0 \mathrm{mmol})$ in THF $(20 \mathrm{~mL})$. The mixture was stirred for $2 \mathrm{~h}$ at room temperature. A solution of isophthaloyl dichloride $(0.10 \mathrm{~g}, 0.50 \mathrm{mmol})$ in THF $(10 \mathrm{~mL})$ was added and the mixture was refluxed for $24 \mathrm{~h}$. The mixture was cooled to room temperature. Water $(30 \mathrm{~mL})$ was added to the filtrate, and the layers separated. The aqueous layer was extracted with dichloromethane $(2 \times 30$ $\mathrm{mL})$. The combined layers were washed with water $(2 \times 30$ $\mathrm{mL})$, dried $\left(\mathrm{MgSO}_{4}\right)$, filtered, and concentrated in vacuo. The crude was recrystallized from hexane: DCM (3:1) to afford compound $7 \mathrm{a}(0.07 \mathrm{~g}, 15 \%)$ as sticky yellow oil. $v_{\max }$ (nujol mull $/ \mathrm{cm}^{-1}$ ): 2919, 2850, 1746, 1660, 1602, 1506, 1465, 1419, 1307, 1286, 1245, 1168, 1079, 1018, 989, 807. ${ }^{1} \mathrm{H} \mathrm{NMR}\left(\mathrm{CDCl}_{3}, 500 \mathrm{MH}_{\mathrm{Z}}\right), \delta: 0.87\left(\mathrm{t}, J 7 \mathrm{~Hz}, 6 \mathrm{H}, 2 \times \mathrm{CH}_{3}\right)$, 1.27-1.84 (m, 32H, $\left.16 \times \mathrm{CH}_{2}\right), 4.04(\mathrm{t}, J 7 \mathrm{~Hz}, 4 \mathrm{H}, 2 \times$ $\left.\mathrm{OCH}_{2}\right), 6.96-8.04$ (m, 16H, Ar-H), 7.53 (d, 2H, J $15 \mathrm{~Hz}, 2 \mathrm{x}$ trans-olefinic $\mathrm{H}), 7.71(\mathrm{t}, 1 \mathrm{H}, \mathrm{Ar}-\mathrm{H}), 7.79-7.82(\mathrm{~d}, 2 \mathrm{H}, J 15$ $\mathrm{Hz}, 2 \mathrm{x}$ trans-olefinic $\mathrm{H}), 8.47-8.49(\mathrm{~d}, 2 \mathrm{H}, J 9 \mathrm{~Hz}, \mathrm{Ar}-\mathrm{H})$, $9.02(\mathrm{~s}, 1 \mathrm{H}, \mathrm{Ar}-\mathrm{H})$. The same general procedure to afford 7b-7c with the scale $(\mathrm{mL}, \mathrm{mmol},[\mathbf{4 b}-\mathbf{4 c}])$ and yields are shown below.

Benzene-1,3-dicarbonyl-bis-1-(4-dodecyloxyphenyl)-3(4hydroxyphenyl)prop-2-en-1-one (7b)

4b $(0.41 \mathrm{~g}, 1 \mathrm{mmol})$. Yield: $(0.08 \mathrm{~g}, 17 \%)$ as sticky yellow oil. $v_{\max }\left(\right.$ nujol mull $/ \mathrm{cm}^{-1}$ ): $2918,2849,1730,1677,1606$, $1579,1508,1463,1361,1277,1253,1178,1111,1026,964$, 842. ${ }^{1} \mathrm{H}$ NMR $\left(\mathrm{CDCl}_{3}, 500 \mathrm{MHz}_{\mathrm{z}}\right), \delta: 0.86(\mathrm{t}, J 7 \mathrm{~Hz}, 6 \mathrm{H}, 2$ x $\left.\mathrm{CH}_{3}\right), 1.38-1.79\left(\mathrm{~m}, 40 \mathrm{H}, 20 \mathrm{x} \mathrm{CH}_{2}\right), 4.01(\mathrm{t}, 4 \mathrm{H}, J 7 \mathrm{~Hz}$, $\left.2 \times \mathrm{OCH}_{2}\right), 6.93-8.01(\mathrm{~m}, 16 \mathrm{H}, \mathrm{Ar}-\mathrm{H}), 7.57(\mathrm{~d}, 2 \mathrm{H}, J 15 \mathrm{~Hz}$, $2 \mathrm{x}$ trans-olefinic $\mathrm{H}), 7.69(\mathrm{t}, 1 \mathrm{H}, \mathrm{Ar}-\mathrm{H}), 7.78(\mathrm{~d}, 2 \mathrm{H}, J 15$ $\mathrm{Hz}, 2 \mathrm{x}$ trans-olefinic H), 8.20-8.21 (d, 2H, Ar-H), 8.67 (s, $1 \mathrm{H}, \mathrm{Ar}-\mathrm{H})$.

Benzene-1,3-dicarbonyl-bis-1-(4-tetradecyloxyphenyl)3(4-hydroxyphenyl)prop-2-en-1-one (7c)

4c $(0.44 \mathrm{~g}, 1.0 \mathrm{mmol})$. Yield: $(0.09 \mathrm{~g}, 18 \%)$ as sticky yellow oil. $v_{\max }\left(\right.$ nujol mull $\left./ \mathrm{cm}^{-1}\right): 2918,2850,1743,1651,1604$, 1546, 1509, 1255, 1225, 1169, 1036, 980, 921. ${ }^{1} \mathrm{H}$ NMR $\left(\mathrm{CDCl}_{3}, 500 \mathrm{MH}_{\mathrm{z}}\right), \delta: 0.84\left(\mathrm{t}, J 7 \mathrm{~Hz}, 6 \mathrm{H}, 2 \times \mathrm{CH}_{3}\right), 1.24-$ $1.81\left(\mathrm{~m}, 48 \mathrm{H}, 24 \times \mathrm{CH}_{2}\right), 4.04\left(\mathrm{t}, J 7 \mathrm{~Hz}, 4 \mathrm{H}, 2 \times \mathrm{OCH}_{2}\right)$, 6.96-8.04 (m, 16H, Ar-H), 7.53 (d, 2H, J $15 \mathrm{~Hz}, 2$ x transolefinic H), $7.70(\mathrm{t}, 1 \mathrm{H}, \mathrm{Ar}-\mathrm{H}), 7.80(\mathrm{~d}, 2 \mathrm{H}, J 15 \mathrm{~Hz}, 2 \mathrm{x}$ trans-olefinic $\mathrm{H}), 8.37$ (d, 2H, Ar-H), 8.85 (s, 1H, Ar-H).

\section{Benzene-1,3-dicarbonyl-bis-3-(4-decyloxyphenyl)-1-} (hydroxyphenyl)prop-2-ene-1-one (8a)

6a $(0.38 \mathrm{~g}, 1.0 \mathrm{mmol})$. Yield: $(0.10 \mathrm{~g}, 11.6 \%)$ as a pale yellowish oil $\mathrm{v}_{\max }\left(\mathrm{KBr} / \mathrm{cm}^{-1}\right)$ 2921(- $\left.\mathrm{CH}_{2}\right), 2851\left(-\mathrm{CH}_{3}\right)$, 1733( $\mathrm{C}=\mathrm{O}$ ester), $1644(\mathrm{C}=\mathrm{O}$ carbonyl), $1222(\mathrm{C}-\mathrm{O}-\mathrm{C})$, 987 $(\mathrm{C}=\mathrm{C}), 825$ (para disub benzene). $\delta_{\mathrm{H}}\left(500 \mathrm{MHz}, \mathrm{CDCl}_{3}\right)$ 0.86 (t, 6H, H3-10"), 1.26-1.78 (m, 32H, H2-2"-9"), 3.99 (t, $4 \mathrm{H}, \mathrm{H}_{2}-1$ "), 6.89-6.96 (m, 8H, H $\mathrm{H}_{1}-2$ "), 7.36-7.37 (t, 1H, $\mathrm{H}_{1-}$ 4), 7.42 (d, $J$ 15.45, 2H, $\left.\mathrm{H}_{1}-\mathrm{b}\right), 7.57-7.60$ (m, 4H, $\mathrm{H}_{1}-3$ ”), 7.78(d, $J$ 16.60, 2H, $\left.\mathrm{H}_{1}-\mathrm{a}\right), 8.09-8.11\left(\mathrm{~d}, 2 \mathrm{H}, \mathrm{H}_{1}-3\right), 8.31$, 8.37(dd, 8H, $\mathrm{H}_{1}-3$ " \& 2"), 8.85(s, $\left.1 \mathrm{H}, \mathrm{H}_{1}-1\right)$.

Benzene-1,3-dicarbonyl-bis-3-(4-dodecyloxyphenyl)-1(hydroxyphenyl)prop -2-ene-1-one (8b)

6b $(0.41 \mathrm{~g}, 1.0 \mathrm{mmol})$. Yield: $(0.21 \mathrm{~g}, 23.2 \%)$ as pale yellowish oil. $v_{\max }\left(\mathrm{KBr} / \mathrm{cm}^{-1}\right) 2924\left(-\mathrm{CH}_{2}\right), 2853\left(-\mathrm{CH}_{3}\right)$, 1694( $\mathrm{C}=\mathrm{O}$ ester $), 1661(\mathrm{C}=\mathrm{O}$ carbonyl), 1278(C-O-C), $940(\mathrm{C}=\mathrm{C}), 763$ (para disub benzene). $\left(500 \mathrm{MHz}, \mathrm{CDCl}_{3}\right)$ 
0.86 (t, 6H, $\mathrm{H}_{3}-12$ "), 1.26-1.71 (m, 40H, $\mathrm{H}_{2}-2$ "-11"), 3.97 (t, 4H, H2-1"), 6.88-6.92 (m, 4H, H1-2"), 7.39-7.40 (t, 1H, $\left.\mathrm{H}_{1}-4\right), 7.45\left(\mathrm{~d}, J 15.45,1 \mathrm{H}, \mathrm{H}_{1}-\mathrm{b}\right), 7.55-7.57\left(\mathrm{~m}, 4 \mathrm{H}, \mathrm{H}_{1}-2\right)$, $7.77\left(\mathrm{~d}, J 16.60,2 \mathrm{H}, \mathrm{H}_{1}-\mathrm{a}\right), 7.87-7.90\left(\mathrm{~d}, 4 \mathrm{H}, \mathrm{H}_{1}-3\right), 7.94$, 7.98 (dd, 8H, $\mathrm{H}_{1}-3$ ” \& 2”), 8.07 (s, 1H, $\left.\mathrm{H}_{1}-1\right)$.

\section{Benzene-1,3-dicarbonyl-bis-3-(4-tetradecyloxyphenyl)-1- (hydroxyphenyl) prop-2-ene-1-one (8c)}

6c $(0.44 \mathrm{~g}, 1 \mathrm{mmol})$. Yield: $(0.20 \mathrm{~g}, 21.5 \%)$ as a pale yellowish oil. $v_{\max }\left(\mathrm{KBr} / \mathrm{cm}^{-1}\right) 2917\left(-\mathrm{CH}_{2}\right), 2849\left(-\mathrm{CH}_{3}\right)$, $1729(\mathrm{C}=\mathrm{O}$ ester $), \quad 1655(\mathrm{C}=\mathrm{O}$ carbonyl $), 1259(\mathrm{C}-\mathrm{O}-\mathrm{C})$, 1021 $(\mathrm{C}=\mathrm{C}), \quad 799$ (para disub benzene). $\delta_{\mathrm{H}}(500 \mathrm{MHz}$, $\left.\mathrm{CDCl}_{3}\right) 0.86$ (t, 6H, H3-14"), 1.24-1.78 (m, 48H, $\mathrm{H}_{2}-2$ "13"), 3.99 (t, 4H, $\mathrm{H}_{2}-1$ ”), 6.89-6.92 (m, 4H, H $\mathrm{H}_{1}-2$ "), 7.35$7.37\left(\mathrm{t}, 1 \mathrm{H}, \mathrm{H}_{1}-4\right), 7.37$ (d, $\left.J 15.45,2 \mathrm{H}, \mathrm{H}_{1}-\mathrm{b}\right), 7.57-7.61$ (m, 4H, H $\mathrm{H}_{1}-3$ "), 7.78 (d, J 15.45, 2H, $\left.\mathrm{H}_{1}-\mathrm{a}\right), 8.09-8.11$ (d, $\left.4 \mathrm{H}, \mathrm{H}_{1}-3\right), 8.31,8.38$ (dd, $8 \mathrm{H}, \mathrm{H}_{1}-3$ " \& 2"), 8.86 (s, $1 \mathrm{H}, \mathrm{H}_{1-}$ $1)$.

\section{RESULTS \& DISCUSSION}

Initial study on the preparation of $\mathbf{2}$ was performed following typical procedure, where earlier synthesized 4hydroxychalcone, $\mathbf{1}$, in tetrahydrofuran (THF) was added into sodium hydride $(\mathrm{NaH})(60 \%)$ and stirred for $1 \mathrm{~h}$ at room temperature. Benzene-1,3-dicarbonyl dichloride in THF was added to the mixture and stirred at room temperature. TLC analysis, however, showed no sign of product formed after $24 \mathrm{~h}$.

Several attempts were made with slight modifications on the reaction condition (solvent, time, temperature), however no evidence for formation of the desired product.

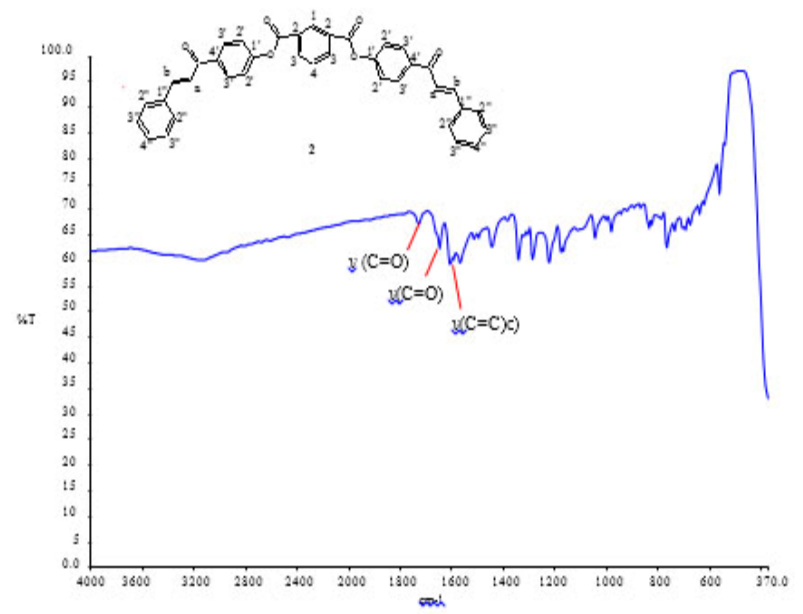

Fig. 1 IR Spectrum of compound (2) using $\mathrm{NaH}(95 \%)$

$\mathrm{NaH}(95 \%)$ was chosen over $\mathrm{NaH}(60 \%)$ as a catalyst and successfully afforded 2 with $50 \%$ yield. The preparation of $\mathbf{2}$ is depicted in Scheme 1.
The chemical structure of 2 was found to be consistent with FT-IR and ${ }^{1} \mathrm{H}$ NMR spectroscopic methods and showed the peaks corresponded to the structures.

The IR spectrum of $\mathbf{2}$ is shown in Fig. 1. The IR spectrum showed the disappearance of $-\mathrm{OH}$ peak at 3140 $\mathrm{cm}^{-1}$ and the appearance of absorption band at $1727 \mathrm{~cm}^{-1}$, which were attributed to the formation of ester bond. The structure of 2 were further confirmed by ${ }^{1} \mathrm{H}$ NMR spectrum (Fig. 2), which showed peaks attributed to trans vinylic proton at $\delta 6.96$ and 7.89, with a coupling constant, Jab 15 $\mathrm{Hz}$. New peak attributed to center aromatic $\mathrm{H}_{1}$ appeared as singlet at $\delta 8.49$. The peaks corresponded to $\mathrm{H}_{3 \& 4}$ were appeared at $\delta$ 7.57-8.08. This proton resonates more downfield from other resonances due to the attachment with two chalcones moieties.

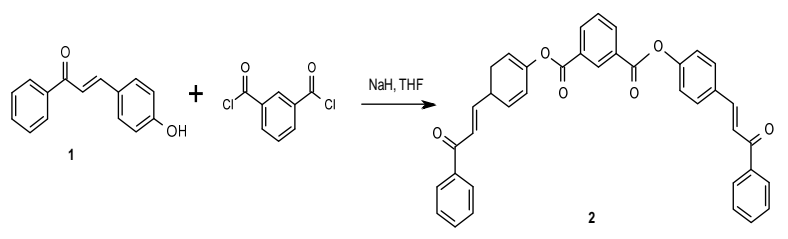

Scheme 1 Model study on the preparation of chalcone ester 2

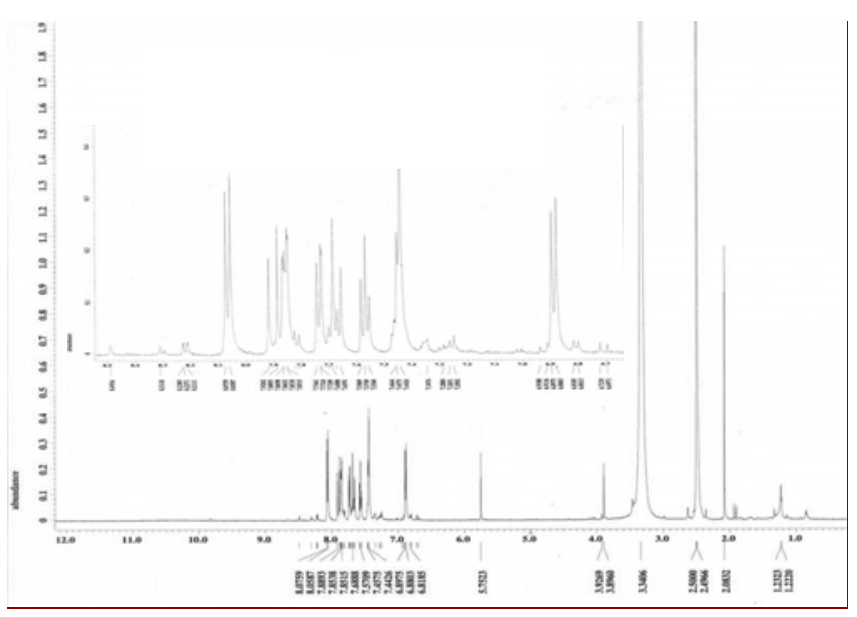

Fig. 2 IR Spectrum of compound (2) using $\mathrm{NaH}(95 \%)$

Several methods have been employed in the synthesis of chalcones due to ease of chalcone structure itself to be substituted [13, 14]. A series of chalcone derivatives (E)-1-[4-(alkyloxy)phenyl]-3-[4hydroxyphenyl ] prop-2-en-1-one (4a-4c) and (E)-3-(4alkyloxyphenyl)-1-(4-hydroxyphenyl)prop-2-en-1-one (6a6c) were prepared via Claisen-Schmidt condensation by the route depicted in Scheme 2.

Compound 3a-c and 5a-c were reacted with 4hydroxybenzaldehyde and 4-hydroxyacethophenone, respectively, under refluxing methanol to afford hydroxylated chalcones $\mathbf{4 a - c}$ and $\mathbf{6 a - c}$ as yellow crystals. IR 
spectra showed the presence of $v_{\mathrm{OH}}$ at $3262 \mathrm{~cm}^{-1}$, while $v_{\mathrm{CH} 2}$ and $v_{\mathrm{CH} 3}$ bands were observed at 2922 and $2851 \mathrm{~cm}^{-1}$ respectively.
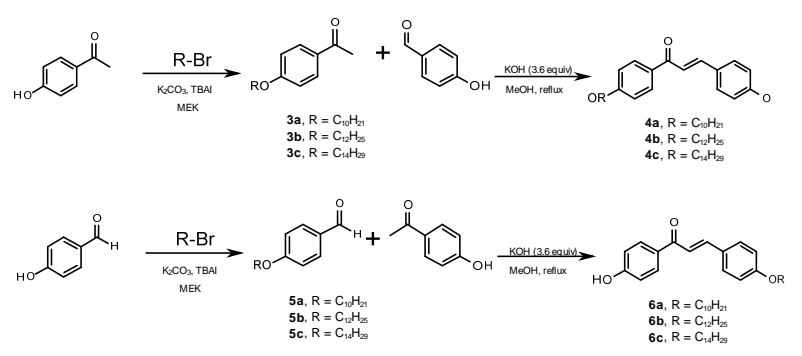

Scheme 2 Synthesis of chalcone derivatives $4 \mathbf{4 a - c}$ and $\mathbf{6 a - c}$

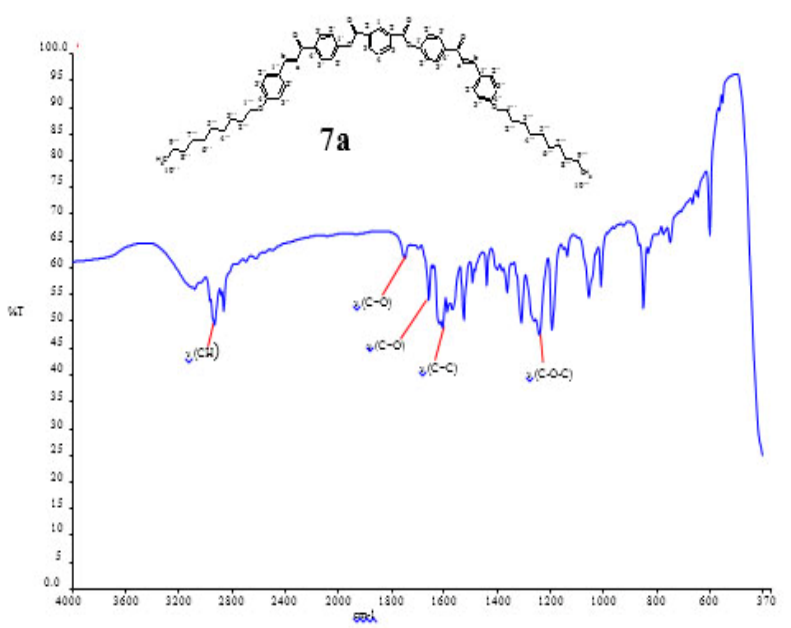

Fig. 3 IR Spectrum of 7a

The structures of compound $\mathbf{4 a - c}$ and $\mathbf{6 a - c}$ were further verified using ${ }^{1} \mathrm{H}$ NMR and ${ }^{13} \mathrm{C}$ NMR analysis. ${ }^{1} \mathrm{H}$ NMR spectra showed the presence of resonances attributed to $\mathrm{CH}_{3}$ and $\mathrm{CH}_{2}$ at $\delta 0.87$ and 1.26-1.83. The trans vinylic proton $\alpha$ and $\beta$ centered at $\delta 7.42$ and 7.74 as two doublets peak with Jab $15.45 \mathrm{~Hz}$. The ${ }^{13} \mathrm{C}$ NMR spectra showed the peak attributed to $\mathrm{C}=\mathrm{O}$ at $\delta 189.1$ and $-\mathrm{COH}$ at $\delta 162.9$.

Compounds 7a-c and 8a-c with two chalcone units were finally prepared by the reaction of $4 \mathbf{a}-\mathbf{c}$ and $\mathbf{6 a - c}$ with isophthaloyl dichloride, respectively. The reactions were performed in the presence of $\mathrm{NaH}(95 \%)$ under refluxing THF to afford 7a-c and 8a-c as viscous yellow oil. The preparation of 7a-c and 8a-c is depicted in Scheme 3.

The IR spectrum of 7a (Fig 3) showed the presence of $v_{\mathrm{c}=\mathrm{o}}$ for ester at $1746 \mathrm{~cm}^{-1}$ and $v_{\mathrm{c}-\mathrm{o}-\mathrm{c}}$ attributed to alkyl aryl ether at $1245 \mathrm{~cm}^{-1}$. The ${ }^{1} \mathrm{H}$ NMR spectrum of 7a (Fig. 4) showed peaks attributed to $\mathrm{CH}_{3}$ and $\mathrm{CH}_{2}$ at $\delta 0.85$ and 1.241.63, while peak attributed to $\mathrm{OCH}_{2}$ at $\delta 3.97$. The trans vinylic proton $\alpha$ and $\beta$ were assigned at $\delta 7.60$ and 7.78 with Jab $15.45 \mathrm{~Hz}$. The attachment of two chalcone units onto the benzene ring was supported by the appearance of a resonance as a triplet and a singlet at $\delta 7.37$ and 8.85 respectively.
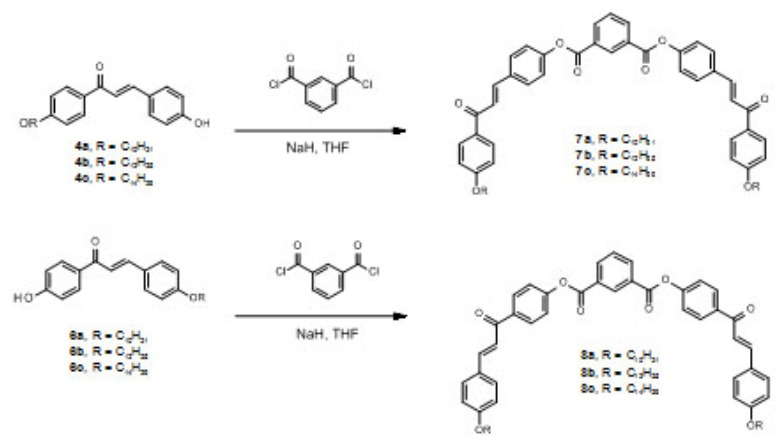

Scheme 3 Synthesis of banana-shaped chalcones ester $7 \mathbf{a}-\mathbf{c}$ and 8a-c

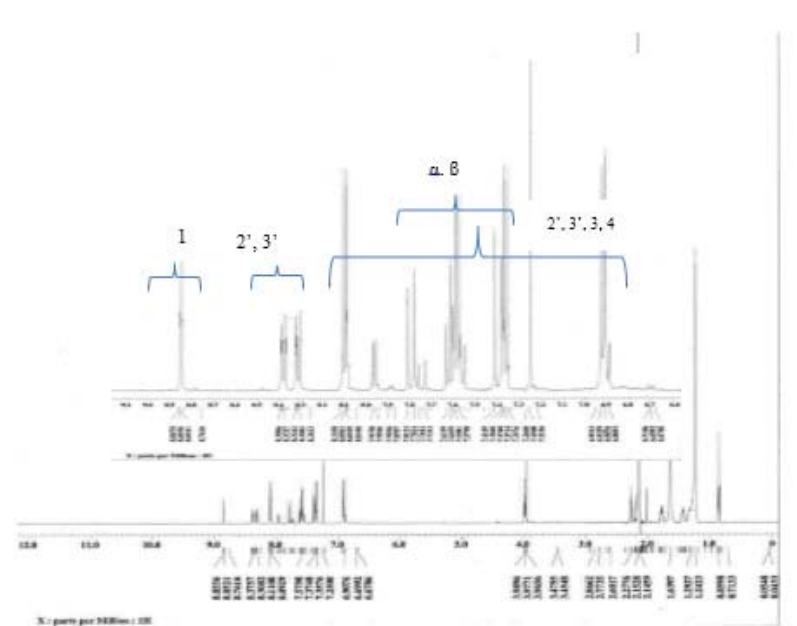

Fig. $4{ }^{1} \mathrm{H}$ NMR spectrum of 7 a

\section{CONCLUSION}

We have synthesised new homologues series of banana-shaped compounds 7a-c and 8a-c comprising bifunctional chalcone units in the presence of $\mathrm{NaH}(95 \%)$. The low yield of 7a-c and 8a-c might due to the steric effect of hydroxylated chalcone 4a-c bearing long alkyl chains. Compounds 7a-c and 8a-c could be useful in the study of banana shaped liquid crystals properties.

\section{ACKNOWLEDGEMENTS}

The authors wish to thank Universiti Malaysia Sarawak and Ministry of Science, Technology, and Innovation (MOSTI) for the financial support through FRGS/01(14)/743/2010 (29). 


\section{REFERENCES}

[1] A. I. Jakli, (2008). United States Patent 20080002121

[2] D. H. Choi, Y. K. Cha, Bull. Korean Chem. Soc. 23 (2002) 587.

[3] S. W. Nam, S. K. Kang, J. Y. Chang, Macromol. Res. 15 (2007) 74.

[4] J. Indira, P. P. Karat, B. K. Sarojini, J. Cryst. Growth 242 (2002) 209.

[5] B. T. Thaker, D. M. Patel, P. K. Tandel, M. S. Jesani, C. J. Vyas, A. D. Vansadia, Phase Transitions 78 (2005) 521.

[6] K. H., Jung, S. Y. Hyun, D. M. Song, D. M. Shin, Opt. Mater. 21 (2002) 663.

[7] B. Zhao, W. Q. Lu, Z. H. Zhou, Y. Wu, J. Mater. Chem. 10 (2000) 1513.

[8] D. Fichou, T. Watanabe, T. Takeda, S. Miyata, Y. Goto, M. Nakayama, Jpn. J. Appl. Phys. 27 (1988) 429.

[9] Y. Shimbo, Y. Takanishi, K. Ishikawa, E. Gorecka, D. Pociecha, J. Mieczkowski, K. Gomola, H. Takezoe, Jpn. J. Appl. Phys. 45 (2006) 282.
[10] J. C. Rouillon, J. P. Marcerou, M. Laguerre, H. T. Nguyen, M. F. Achard, J. Mater. Chem. 11 (2001) 2946.

[11] Z. Ngaini, N. I. Abdul Rahman, Can. J. Chem. 88 (2010) 654.

[12] Z. Ngaini, N. I. Abdul Rahman, Phosphorus, Sulfur Silicon Relat. Elem. 185 (2010) 628.

[13] B.A., Bhat, K. L. Dhar, S. C. Puri, A.K. Saxena, M. Shanmugavel, G.N. Qazi, Chem. Lett. 15 (2005) 3177.

[14] K. Yoshizawa, and T. Shioiri, Tetrahedron Lett. 47 (2006) 4943. 